distinguished by the importance it attaches to large step changes and the pressure of macromutations, over and above natural selection.

How well has Løvtrup succeeded in clarifying these important and difficult issues? Reluctantly, I must suggest that in large measure he has been unsuccessful, though whether this is due to the unsuitability of the methods adopted, or to the way these are used, is not a question that can be answered here. His arguments are based on formal language but are often illogical and imprecisely formulated. He purports to follow Popper but his theories are often unfalsifiable in principle or protected by phrases such as "Other things being equal". Large sections of the argument about relationships are indistinguishable from induction by enumeration and from the search for confirmation, as is shown by the repeated use of statements such as, "If we want to find support for the classification in Figure 4.12, we must look for characters in common between Caudata and Salientia".

The section which purports to confront his theory of vertebrate interrelationships with the facts of the fossil record, seems to rely heavily on the interpretation of the facts in the light of the theory they are said to support. Yet even this will not dispose of the Placodermi, which are therefore dismissed with an astonishingly vacuous quotation from Romer, which is said to seem "to be quite a close approximation to the truth". Unfortunately, the form of the argument is also imprecisely handled and this hinders comprehension. Some axioms are either self-contradictory or ambiguously stated, others are stated and then immediately refuted, and yet others introduced with an exception that is not defined until much later. At least one theory is a paraphrase of the definition from which it is said partly to be derived, and another is incompatible with the theory from which it is said to be deduced.

These are harsh criticisms of an honest attempt to deal in an explicit way with a number of difficult problems. I share L $\phi$ vtrup's views on the importance of criticism and on the seriousness of the failure of many comparative biologists to make their assumptions, arguments and conclusions clear. Therefore, I recommend this book, particularly to those involved in tracing the history of life. For, despite its failures, it is full of challenging ideas, and I unreservedly commend the attitudes and hopes that motivated its writing.

R. S. Miles

R. S. Miles is Head of the Department of Public Services at the British Museum (Natural History).

\section{Ellipsometry and polarised light}

Ellipsometry and Polarized Light. By R. M. A. Azzam and N. M. Bashara. Pp. xvii+529. (North-Holland: New York, Amsterdam and Oxford, 1977.) Dfl.180; $\$ 37.50$.

Ellipsometry is a technique for examining the optical properties of surfaces and thin films with polarised electromagnetic radiation. The technique is intrinsically very sensitive and deceptively simple in principle. Thus, it can readily be explained at a superficial level to students with only a minimal grasp of optics. Scientists who apply ellipsometry to investigate a wide range of phenomena, however, are aware of the need to take account of many possible sources of systematic error and of the consequent notorious difficulties in interpreting ellipsometric observations. The publication of a book of five hundred pages on ellipsometry will therefore not surprise them. Indeed, English-speaking scientists will welcome the first book of its kind written in their language by authors with international reputations for contributions to the development and use of ellipsometry.

The first two chapters are devoted to descriptions of well established and predominantly matrix methods of representing polarised radiation and the operation of optical elements with polarising properties. In chapter three the authors give an analysis of the main ellipsometric arrangements and a well ordered discussion of associated systematic errors; essentially the core

\section{Ethological dictionary}

Ethological Dictionary. By Armin Heymer. Pp. 237. (Paul Parey: Berlin and Hamburg, 1977.) DM28.

A dictionary in three languages (German, English, French) such as this one is useful to both students and research workers if it contains a wide enough selection of terms. I carried out a quick test by opening a recent textbook of animal behaviour at two randomly chosen pages. The Dictionary scored only a $40 \%$ success rate on the first ten technical terms encountered. Territoriality, echolocation, circadian rhythm and orientation were included and adequately defined, but habituation, phonoresponse, species recognition, arousal, sexual selection and selective attention were not listed. material of the book. The procedures for relating observable optical func. tions to the macroscopic optical constants of the materials of thin films and surfaces are presented in chapter four. Much of its contents can be found in other texts on thin film optics, but the account has been updated by references to recent work on anisotropic crystalline materials, as well as by a discussion of numerical inversion procedures. An account of instrumentation is given in chapter five with emphasis on imperfections and automation. In the final chapter, the authors provide a necessarily brief survey of the very wide range of physical surface investigation which has prompted the application of ellipsometry. Examples are taken from optics, physical chemistry, electrochemistry, particle radiation physics and biology.

The book is well written, with clear diagrams and few typographical errors. A pleasing feature of style are the separate introductions to each chapter, which provide the reader with a general preview of what is to follow. On the other hand, the balance of the material, which presumably reflects the authors' particular interests, will not be to the taste of some readers. For instance, the mathematical representations of polarised radiation are treated exhaustively at the expense of explanations of the underlying physical phenomena. A prominent example of inadequate emphasis concerns the ultimate sensitivity of ellipsometers; an important matter dismissed in a single paragraph.

P. H. Lissberger

P. H. Lissberger is Professor of Physics at the Queen's University, Belfast, Northern Ireland.

Admittedly this is a small sample, but several of the missing terms are very common in ethological literature.

The dictionary does, however, score well in including some obscure terms with which I was not familiar. "Night dancers" are "bees that dance at 3.22 a.m. with only $12.5^{\circ}$ error in the waggle dance", and equally intriguing "shag time" is apparently slang for "breeding season in hares and rabbits".

In general, the technical terms included in the dictionary and the way in which they are defined very much reflect the Lorenzian school of ethology, so that the dictionary might prove useful to those wishing to delve into the earlier German literature. Other users may find the range of terms covered too limited for the book to be worth buying as an all round aid to translation.

John Krebs

John Krebs is Lecturer in Zoology at the Edward Grey Institute of Field Ornithology, Oxford, UK. 